Can lobbying encourage abatement? Designing a new policy instrument

Ian Lange

Sarah Polborn

Stirling Economics Discussion Paper 2012-03

March 2012

Online at

http://www.management.stir.ac.uk/research/economics/workingpapers 


\title{
Can lobbying encourage abatement? Designing a new policy instrument
}

\author{
Ian Lange* Sarah Polborn ${ }^{\dagger}$
}

February 24, 2012

\begin{abstract}
Taking a political economy perspective this paper proposes an alternative carbon abatement policy instrument with significant advantages over existing policy instruments. The key feature of the proposed carbon securities is that they entitle their owners to a fixed proportion of ex ante unknown total emissions. The total level of carbon emissions is set by the political process after the carbon securities have been sold. A key benefit of the proposed carbon security is that it creates a group of stakeholders, whose interest is for a smaller level of emissions and which competes with industries that consume significant amounts of carbon-based energy. The advantages over existing policy tools include an equilibrium carbon price closer to the level preferred by voters and a more predictable environmental policy in the presence of either climate or political uncertainty. (JEL: D72, Q54, Q58)
\end{abstract}

*Division of Economics, University of Stirling, Stirling FK9 4LA UK i.a.lange@stir.ac.uk +44(0)1786467276

${ }^{\dagger}$ Department of Economics and Business, Aarhus University, Frichshuset, Hermodsvej 22, DK-8230 Aabyhoj, Denmark sarahp@asb.dk +45 89488935 


\section{Introduction}

There is strong evidence that to maximize the present value of world income a reduction of carbon dioxide emissions by at least 10 percent is advisable. Global agreement on carbon emission reductions has been difficult to come by. The costs of this suboptimal policy choice are likely in the range of 3 to 6 trillion 2005 US dollars and possibly higher (Nordhaus (2010b), Keller et al. (2007)).

Industry interests are partially responsible for the failure of governments to pass appropriate climate legislation since the design of environmental policy is subject to pressures from industrial lobbies. ${ }^{1}$ An example is the US climate change bill that was eventually rejected in the Senate in 2010. As a whole the US economy would most likely not be significantly hurt by moderate carbon abatement, but certain industries - in particular oil and coal - would be. It is not surprising that these industries mounted a large lobbying campaign to protect their interests. ${ }^{2}$ In many countries, there are well financed, influential lobbies which successfully represent the interests of industries that benefit from a low level of carbon abatement. The outcome is frequently the implementation of a policy that deviates from the social welfare maximizing policy and makes concessions to interest groups (Markussen and Svendsen (2005), Ekins and Speck (1999)).

There are two classes of market-based policy instruments currently used and/or debated to regulate carbon dioxide emissions: taxes and permits (cap and trade). A large literature discusses the advantages and disadvantages of these two policy instruments from a variety of perspectives. ${ }^{3}$ Keohane (2009) and Metcalf (2009) debate each instrument's relative merits. Hahn (2009) discusses the two policy instruments with a focus on how the government

\footnotetext{
${ }^{1}$ See for example the essays collected in Stavins (2004).

${ }^{2}$ In the years 2009 and 2010 firms from the U.S. oil and gas sector spent $\$ 321$ million on lobbying, while electric utilities spent in the same period an additional $\$ 336$ million. (Source: Center for Responsive Politics).

${ }^{3}$ The idea of using a tax to regulate pollution dates back to Pigou (1920). Tradable permits were first suggested in Crocker (1966) and Dales (1968).
} 
would use the revenue generated from each instrument. Goulder et al. (1999) and Bovenberg et al. (2008) compare taxes and permits in a second-best setting of pre-existing taxes and industry compensation requirements respectively. Oates and Portney (2003), Stavins (2004) and Keohane et al. (2002) discuss political economy aspects of policy instruments. In other related work, Lai (2008) constructs a two-stage lobbying game to explain why some fraction of permits are typically grandfathered while the remaining permits are distributed through auctions. Hanley and MacKenzie (2010) use a contest model to analyze the incentives to rent seek for pollution permits and to analyze the consequences for social welfare.

This paper proposes a policy instrument, that has to our knowledge not been proposed previously and that we will refer to as carbon securities. A carbon security gives the owner of the security the right to emit (or to sell this right) in each of the following $k$ periods up to $\frac{1}{n} X_{j}$, where $X_{j}$ is the society's total desired carbon emissions for period $j$ and $n$ is the total number of securities sold. The sequence of amounts $\left\{X_{j}\right\}_{1}^{k}$ is unknown to any potential buyer of the security at the time when she has to decide whether she wants to purchase a security. At the beginning of period $j$, the political process determines the society's total desired carbon emissions, $X_{j}$. When choosing $X_{j}$ the political process takes into account the voters' preferences and any contributions from lobbies representing either the interests of the carbon-using industry or the owners of carbon securities. Our approach to modeling the political process is inspired by Grossman and Helpman (1994), whose pioneering approach has been applied to a wide variety of policy issues. In particular, Aidt (1998) uses a common agency framework to derive the characteristics of endogenous environmental policy.

The main advantage of carbon securities is that they create stakeholders with an interest in lobbying for low carbon emissions. The idea is that active participation of this group in the policy-making process counterbalances the lobbying of industries that benefit from a low level of carbon abatement, in the following referred to as the carbon-using industry. Research 
on lobbying decisions by firms finds that the high fixed costs to begin the lobbying process is very important (Bombardini (2008) and Kerr et al. (2011)). Once a firm has engaged in lobbying, they are highly likely to continue. The proposed policy instrument helps firms overcome the fixed cost of lobbying with the promise of a greater payoff of their pre-purchased securities. Once purchased, these securities would be sunk capital to the owners. It has been shown that owners of sunk capital are more willing to pay for lobbying than owners of assets that can easily to transformed to alternative uses (Marceau and Smart (2003)).

While both emission permits and carbon securities establish property rights, there are some important differences. Permits give the owner the right to emit a fixed amount of carbon which is set prior to the sale of the permit. Once permits have been distributed, the cap is set. Lobbying to decrease the cap and thereby increase the value of the purchased permits is unlikely to be successful since it would require that the government buys back permits. As a result, groups which might be interested in higher prices of the permit have lost the opportunity to lobby for them. Carbon securities entitle the owner to a fixed proportion of total emissions, which have not yet been set at the time when the securities are sold.

We depart from previous studies in two important ways. First, we propose a new policy instrument that encourages the formation of a counter-lobby to the existing lobby groups representing the carbon-using industries. The model suggests that the lobbying process with carbon securities leads to a carbon price level that is closer to the carbon price level preferred by the median voter than with a tax or permit system. This is a direct consequence of the presence of stakeholders with an interest in low carbon emissions. Second, we study the effect of climate and political uncertainty on the variance of the carbon price. While there is ex ante uncertainty about the amount of carbon emissions allowed per security, the variance of the expected carbon price is smaller. 


\section{The Model}

We compare the performance of a carbon tax and of carbon securities within two period games. Figure 1 shows a timeline for a two period model in which securities are sold in the first period and pay one carbon allowance in the second period. For ease of exposition, we focus on this two period model. An $k+1$ period model with securities that pay $k$ allowances is a fairly straightforward extension. ${ }^{4}$

At the beginning of the first period, the government announces the policy instrument of its choice. If carbon securities are the chosen policy instrument, the government sells the securities. ${ }^{5}$ There are $m$ identical carbon-using firms. Carbon securities are either bought by carbon-using firms or by investors who do not belong to the carbon-using industry. We first focus for ease of exposition on the benchmark case in which all securities are held by outsiders to the carbon-using industries and then elaborate on what happens if this is not the case. ${ }^{6}$ The carbon-using industry and the owners of carbon securities each organize themselves as a lobby.

In the second period, information about the state of the world, $\theta$, is revealed. The lobby or lobbies then offer their contribution schedule(s) which are conditional on the carbon price selected. The government chooses the level of the carbon price that maximizes its welfare. Then each owner of a carbon security sells her carbon allowance, $\frac{1}{n} X$, to firms required to hold a carbon allowances equal to their carbon emission in period 2. Below we describe the stages of the games in more detail starting with the last stage and with a focus on the more

\footnotetext{
${ }^{4}$ The $k+1$ period model is a repeated game in periods 2 to $k$. The lobbying game described in this section is the a stage game of this repeated game.

${ }^{5}$ The sale of the carbon securities is not explicitly modelled here. Conducting an auction has some well known advantages. However, all results of the paper also follow thorough if the carbon securities would be sold at a fixed price (which could be zero).

${ }^{6}$ The effectiveness of carbon securities as a policy tool depends on the allocation of the carbon securities in the second period. The benefits of carbon securities increase with the fraction of the securities held for investment purposes (resale) and not for a firm's own carbon consumption. See Section 3.5 for more on this issue.
} 


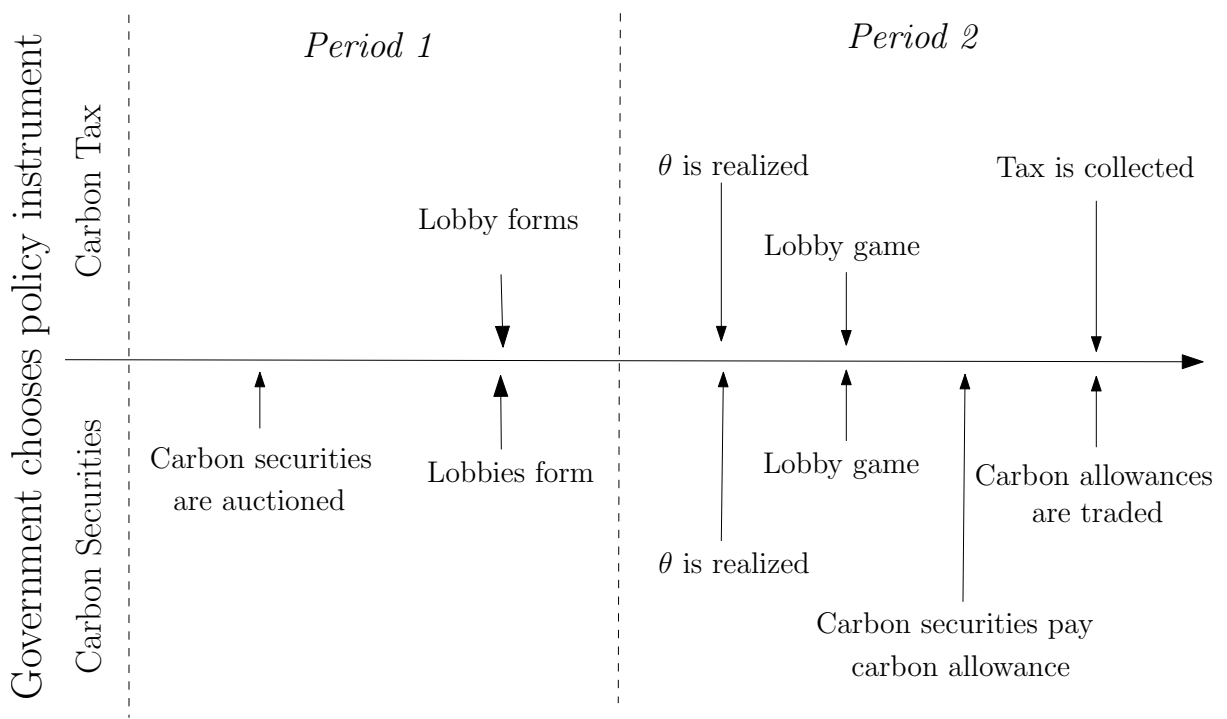

Figure 1: Timeline

complex game with carbon securities as policy instrument.

Consider period 2 of the carbon securities game. Assume demand for carbon inputs, $D$, can be approximated as deterministic. Then total emissions, $X$, determine the carbon price via $D(p)=X$ where $D$ is a decreasing function of the carbon price $p$. The carbon price can be thought of as a fee to be paid per unit of carbon-emitting input (fossil fuels) used in the production process. So the cost of using one unit of carbon-emitting input is the sum of the price of the carbon-emitting input and the carbon price. We limit ourself to the case that the carbon price is non-negative. With a carbon tax the government sets the price of carbon $p$ directly by means of a unit tax. For ease of comparison between the tax and the carbon securities, the government's choice variable is the carbon price in both scenarios.

We assume that the incumbent government believes that its odd of survival depends on how close their chosen policy level is with the policy level preferred by voters. Choosing a carbon abatement policy that displeases many voters decreases the chance to be reelected. At the same time, contributions from lobby groups can be used to finance campaign spending 
and thereby improve reelection prospects. Based on these considerations, we model the government's objective as maximizing its welfare, $W_{G}$, which is equal to the weighted sum of campaign contributions and the benefits of choosing a policy level inline with voters' opinion:

$$
W_{G}(p)=C_{B}(p)+C_{E}(p)-\theta F(p)
$$

$C_{B}$ and $C_{E}$ are the campaign contributions of the carbon securities holders $(B)$ and the carbon-using industry $(E)$, respectively, and $F$ is the cost of deviating from voters' opinion. The variable $\theta$ is the government's preference variable and describes the weight the government gives to campaign contributions relative to the cost of deviating from voters' opinion. We assume that $\frac{\partial F}{\partial p \partial p}>0$ and $F$ has a unique minimum, $p^{*}$, the carbon price that the median voter considers as optimal. While we do not attempt to derive the median voter's preferences from micro foundations, one way to think of $F$ and $p^{*}$ is as the outcome of a tradeoff between the cost of climate change and the benefits of a low price of energy. If $F_{C L I}$ is the voter's estimate of the cost from climate change and $F_{P O L}$ is her estimate of cost resulting from carbon abatement policy then

$$
F(p)=F_{C L I}(p)+F_{P O L}(p) .
$$

It is natural to think of $F_{C L I}$ as an increasing function of total emission $X$ or alternatively as a decreasing function of $p$. Cost resulting from carbon abatement policy, $F_{P O L}$, increase with abatement effort and hence with $p . F, F_{C L I}$ and $F_{P O L}$ are illustrated in Figure 4. Note that if the government was not influenced by interest groups, the government would choose the level of carbon abatement preferred by the median voter as in a standard Downsian model. ${ }^{7}$ Here we assume that governments are influenced by interest groups and therefore look at a second-best equilibrium.

\footnotetext{
${ }^{7}$ In a Downsian model with office motivation and a unidimensional policy space the candidates locate at the median ideal policy in equilibrium (Downs (1957) and Hotelling (1929)).
} 
Next, consider the lobbying stage of the game. We assume that the firms of the carbonusing industry are able to organize themselves into a lobby group in order to influence the political process.

The gross of contributions welfare of the carbon-using industry is

$$
W_{E}(p)=\Pi(p)
$$

where $\Pi(p)=\sum_{i=1}^{m} \pi_{i}(p)$ is the total profit of the industry. An individual firm's profit is $\pi_{i}(p)$ where carbon price $p$ is an input price. So an individual firm's demand for carbonbased inputs is $-\pi_{i}^{\prime}(p)$ and the industry's demand is $D(p)=-\Pi^{\prime}(p)=-\sum_{i=1}^{m} \pi_{i}^{\prime}(p)$ where we use the prime (') notation to indicate derivatives with respect to $p$. The lobby of the carbon-using industry chooses the contribution function $C_{E}$ to maximize net of contributions industry welfare: $\max _{C_{E}} \Pi(p)-C_{E}(p)$. Next, consider the welfare of the owners of the carbon securities. Initially assume that this group is distinct from the group of carbon-using firms. However, in Section 3.5 we analyze the model with this assumption relaxed. The gross of contributions welfare of the owners of carbon securities is the value of the securities in the second period minus the sale price of the securities in the first period:

$$
W_{B}(p)=-p \Pi^{\prime}(p)-\xi n
$$

where $\xi$ is the price that the government sold a security for and $n$ is the total number of securities. The revenue of the owners of the securities is the product of the carbon price and the emission quota. The carbon price is determined by the allowance market equilibrium condition, $D(p)=X$. Anticipating this equilibrium, the owners of carbon securities expect their revenue to equal $-p \Pi^{\prime}(p)$. We assume that the owners of the carbon securities are able 
to organize themselves into a lobby group in order to influence the political process. ${ }^{89}$

\section{Analysis}

\subsection{A Carbon Tax}

When studying the performance of carbon securities we use a carbon tax as the reference point. Since we assume that the demand for carbon inputs is deterministic, it does not make a difference whether the carbon price is chosen by the government or whether the corresponding emission quantity is chosen. Both lead to the same equilibrium.

To find optimal campaign contributions and the equilibrium carbon price level, we use a standard equilibrium concept that is a natural extension of Bernheim and Whinston (1986) (see Appendix for details) and focus on truthful strategies. ${ }^{10}$

Definition 1. A truthful contribution schedule takes the form

$$
C_{j}\left(p, B_{j}\right)=\max \left[0, W_{j}-B_{j}\right]
$$

where $B_{j}$ is a constant and $j=E, B$.

To derive the first order condition characterizing the equilibrium carbon price, take equation (1), apply the definition of truthful strategy and substitute in the expressions in equations

\footnotetext{
${ }^{8}$ In practice, the assumption that a lobby forms is more credible for carbon securities that establish long-term property rights to carbon emissions since the initial cost of setting up a lobby are more likely offset by benefits of a higher value of carbon securities. There may also be concerns that ownership may end up being too dispersed. However, even if just some carbon security holders would form a lobby, the results of Section 3.5 show that a higher carbon price would be implemented.

${ }^{9}$ In addition to the two lobby groups we consider, one may also think of environmental interest groups. We assume that if carbon securities were introduced, the lobbying and fundraising efforts of environmental interest groups are likely to either stay the same or to decrease. Overall, the effect of environmental interest groups is likely to be fairly modest compared to industry lobby groups.

${ }^{10}$ In general, there are a large number of equilibria in menu auctions. However, only equilibria supported by so-called truthful contribution schedules are stable to non-binding communication among players. Also, the best response set to any strategy played by an opponent includes a truthful strategy(Bernheim and Whinston (1986)). Therefore, we focus in the following on equilibria supported by truthful contribution schedules.
} 
(3) and (4). The carbon tax equilibrium carbon price, $p_{T}$, satisfies

$$
\theta F^{\prime}(p)=\Pi^{\prime}(p)
$$

so that marginal campaign contributions equal the weighted marginal cost of deviating from voter opinion.

Proposition 1. The carbon price under a tax system is lower than the median voter's preferred carbon price: $p_{T}<p^{*}$.

The is evidence that supports the position that the pattern predicted by the above proposition is in line with real-world observations. According to Nordhaus (2010b) the current actual carbon price is approximately $\$ 5$, while the current social welfare (discounted GDP) maximizing carbon price is $\$ 30$ (value in 2010, increasing over time) and the carbon price needed to reach the $2^{\circ} \mathrm{C}$ goal is $\$ 59$. If the median voter would be more inclined to follow the Stern Review (Stern, 2007) and its lower discount rate, than the difference between the actual and the social welfare maximizing current carbon price (\$85) would be even larger.

\subsection{Carbon Securities}

The key feature of a system with carbon securities is that the amount of carbon emissions allowed per security is determined after the security has been sold. This provides an incentive for competition among interest groups over the carbon price. With a carbon tax, only the carbon-using industry has a strong financial incentive to lobby for a carbon price in its favor. Introducing property rights for emissions creates a counterbalancing force: now there is a group that has a strong financial interest in lobbying for a high carbon price.

If contribution schedules are truthful, the carbon securities equilibrium carbon price $p_{S}$ satisfies 


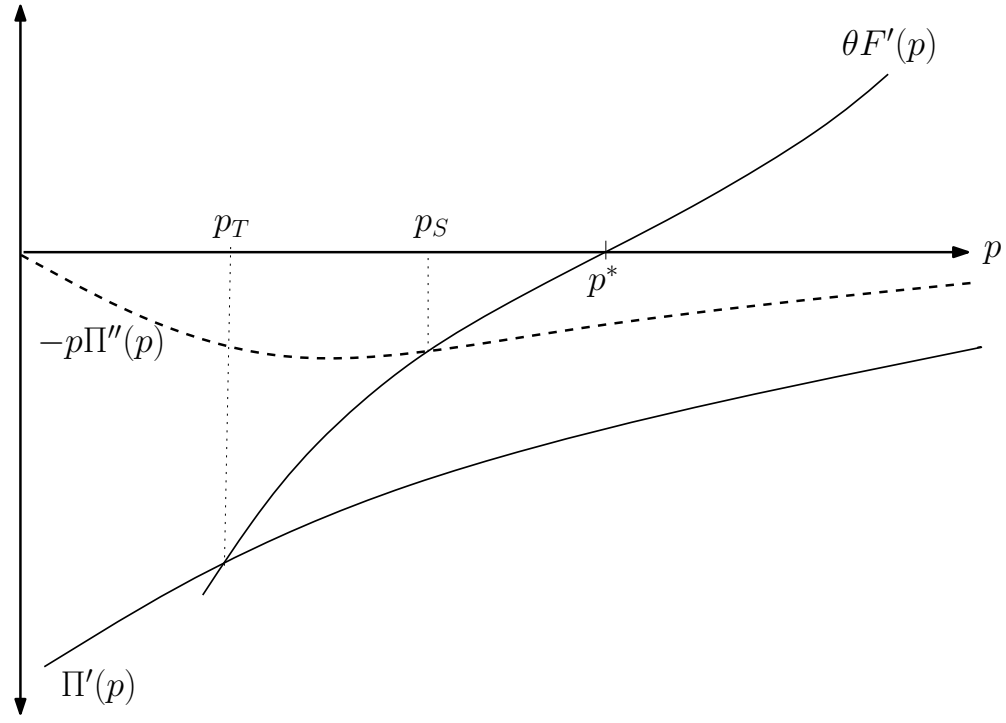

Figure 2: The equilibrium carbon price with carbon securities, $p_{S}$, is higher than the equilibrium price with a carbon tax, $p_{T}$.

$$
\theta F^{\prime}(p)=-p \Pi^{\prime \prime}(p)
$$

The government selects a carbon price that equates the weighted marginal loss from deviating from voters' opinion with the marginal campaign contributions it receives. Campaign contributions are from two sources here: the carbon using industry and the carbon security holders. If the government increases the carbon price, it receives less contributions from the carbon-using industry and higher contributions from the carbon security holders.

Proposition 2. The carbon price under either system is below the median voter's preferred carbon price: $p_{T}<p^{*}$ and $p_{S} \leq p^{*}$. With carbon securities the carbon price is higher than with a tax: $p_{T}<p_{S}$.

Figure 2 illustrates Proposition 2: the intersection of the solid lines indicates the tax equilibrium, the intersection of the dashed line and the solid line the carbon securities equi- 
librium. First, consider the tax equilibrium: Marginal campaign contributions, $\Pi^{\prime}(p)$ are an increasing function, since demand for carbon-based inputs, $-\Pi^{\prime}(p)$, is a decreasing function. Weighted marginal loss from deviating from voters' opinion, $\theta F^{\prime}(p)$, is an increasing function that intersects with the horizontal axis at $p^{*}$, the carbon price preferred by the median voter. The carbon tax equilibrium price is $p_{T}$. Second, consider the carbon securities equilibrium: If demand for carbon-based inputs is inelastic, which will be assumed in the following, then $-p \Pi^{\prime \prime}(p)>\Pi^{\prime}(p)$ and the carbon securities equilibrium carbon price, $p_{S}$, has to be higher than $p_{T}{ }^{11}$

Intuitively, the carbon price is higher with carbon securities since the presence of the lobby of carbon security holders mitigates the influence of the lobby of the carbon-using industry. The size of the effect depends on $\theta$, on the carbon-using industry's profit function and on how sensitive the loss from deviating from voters' opinion is to carbon price changes.

\subsection{Climate and Political Uncertainty}

Suppose that there are two political parties and that there is an election between period 1 and 2. One party has a high $\theta, \theta_{H}$, and the other has a low $\theta, \theta_{L}$ and in period 1 it is uncertain which party will win the election. Figure 3 illustrates this scenario from the perspective of period 1 and therefore shows both possible outcomes. If the party with the high $\theta$ is elected, then irrespective of the policy instrument, the abatement level will be fairly close to $p^{*}$ since a party with a high $\theta$ has a strong preference for being in line with public opinion when it comes to carbon abatement policy. If the party with the low $\theta$ is elected, then with a carbon tax a carbon price significantly below $p^{*}$ is chosen but with carbon securities the carbon price

\footnotetext{
${ }^{11}$ Numerous empirical studies show that demand for carbon-based energy sources is typically inelastic. In the gasoline market, Knittel (2012) overviews the literature. For natural gas, Davis and Muehlegger (2010) find that residential and commercial consumption is highly inelastic. Cooper (2003) calculates crude oil demand elasticities for a sample of 23 countries and finds that both short and long run demand is highly insensitive to price changes.
} 


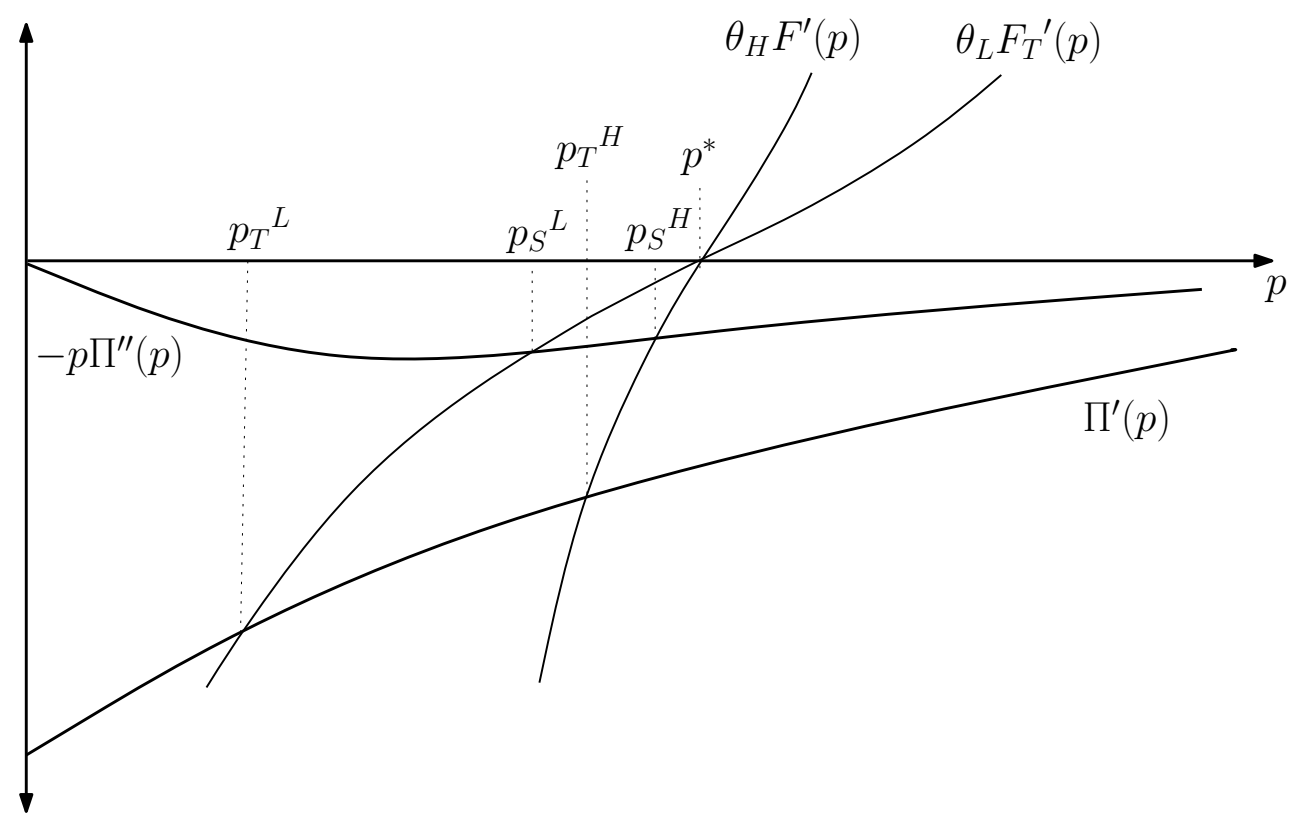

Figure 3: The effect of political uncertainty.

is fairly close to $p^{*}$. The distance between $p_{S}{ }^{L}$ and $p_{S}{ }^{H}$ is smaller than between $p_{T}{ }^{L}$ and $p_{T}^{H}$. So the period 1 variance of the expected carbon price is smaller with carbon securities as policy instrument. Thus, a significant advantage of carbon securities is that they make environmental policy more predictable under this type of political uncertainty.

This result may surprise given that one of the often proclaimed advantages of a carbon tax is the predictability of the carbon price. In our view this argument ignores the fact that tax rates can easily be changed when governments or the political situation changes. ${ }^{12}$

Now assume that there is no political uncertainty but there is considerable uncertainty about the climate and $G_{W}$. For very high carbon emissions (low carbon price), there is a wide range of estimates of the resulting temperature increase and hence the cost of climate change (Allen et al., 2009). There is less uncertainty about the effect of emitting small additional

\footnotetext{
${ }^{12}$ Marsiliani and Renström (2000) address this time-inconsistency problem in tax policy and suggest tax earmarking as a way to imposes a constraint on government policymaking.
} 


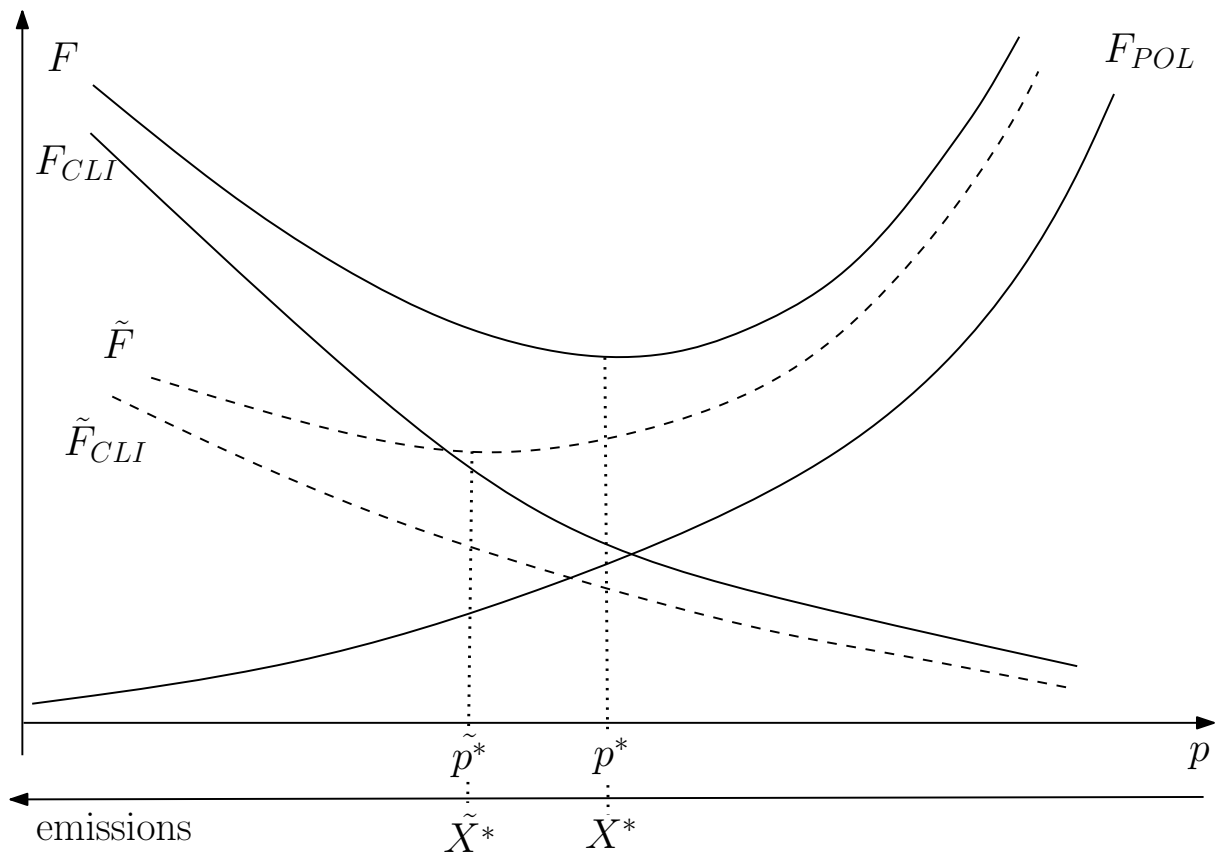

Figure 4: Uncertain cost of climate change.

amounts of carbon. This situation is illustrated in Figure 4 by two $F_{C L I}$ functions: $F_{C L I}$ and $\tilde{F}_{C L I}$ which converge for very low emissions (high carbon prices) but diverge for high emissions. The state of the world characterized by $\tilde{F}_{C L I}$ can be interpreted as a state with either low climate sensitivity or efficient geoengineering options.

Suppose that in period 1 it is unknown whether the loss from deviating from voters' opinion will be characterized by $F_{C L I}$ or $\tilde{F}_{C L I}$. The carbon price the median voter prefers in period 2 can be either $\tilde{p}^{*}$ or $p^{*}$, the minimizers of $F$ and $\tilde{F}$, respectively. The state of the world characterized by $F_{C L I}$ can be thought of as a state with high climate sensitivity and climate change imposing significant cost.

Figure 5 shows $\theta F^{\prime}(p)$ and $\theta \tilde{F}^{\prime}(p)$ to study the effect of this form of climate uncertainty on the respective equilibria under the two policy instruments we compare. Since the distance between $p_{S}^{\tilde{F}}$ and $p_{S}^{F}$, the potential carbon prices with securities, is smaller than between 


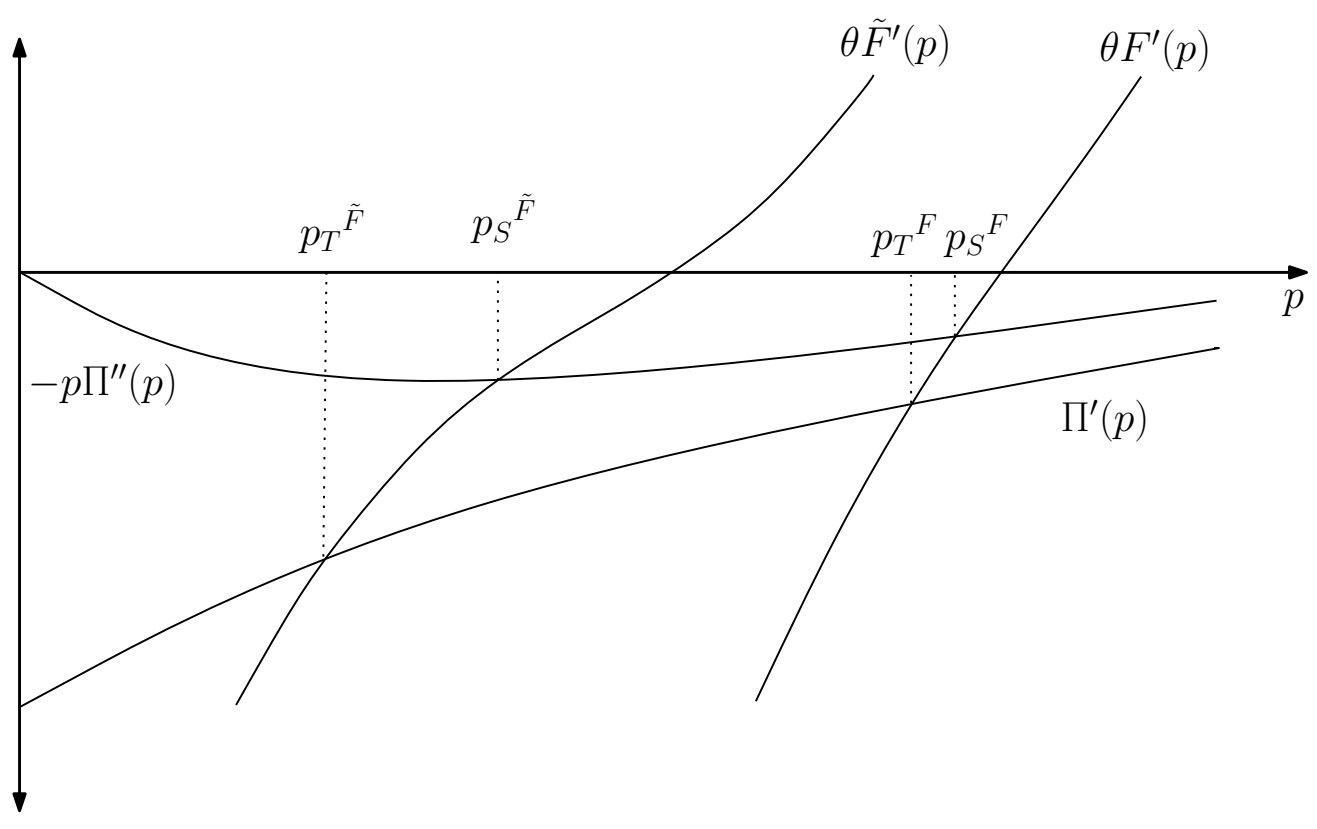

Figure 5: The effect of climate uncertainty.

$p_{T}^{\tilde{F}}$ and $p_{T}^{F}$, the potential carbon prices with a tax, the period 1 variance of the carbon price is smaller with carbon securities. So with respect to the possibly most important type of uncertainty related to carbon abatement policy, the unpredictability of the costs associated with very high carbon emissions, carbon securities reduce the variance of the carbon price and thereby make environmental policy more predictable. A more predictable environmental policy could encourage investment in carbon abatement technology.

\subsection{Discussion}

This section discusses (i) the performance of carbon securities when some carbon-using firms purchase carbon securities, (ii) the attractiveness of carbon securities to politicians, and (iii) the practical implementation and monitoring burden.

If an outsider of the carbon-using industry owns a carbon security, this investor prefers 
a carbon price that maximizes the value of the carbon securities. This changes if a carbon security is held by an insider of the carbon-using industry. An insider owns carbon securities for his own consumption of carbon allowances and possibly in addition to that in order to sell any left over carbon allowances to other firms. The insider prefers an emission quota high enough so that her own carbon emissions are covered by her carbon allowances. However, for selling any left over allowances, a high carbon price is advantageous. ${ }^{13}$

Suppose that of the $m$ identical firms in the industry, a fraction $\alpha$ holds the $n$ securities and that each of these $\alpha m$ firms holds the same share of the carbon securities. The remaining firms have to purchase emissions allowances from these $\alpha m$ firms.

Let $p_{T}$ and $p_{S}$ again be the $100 \%$ outsider ownership equilibrium prices derived earlier and $p_{\alpha S}$ the equilibrium price if a fraction $\alpha$ of carbon-using firms owns all securities.

Proposition 3. The equilibrium price if $\alpha m$ firms own the $n$ securities lies between the tax equilibrium price and the carbon securities equilibrium price with $100 \%$ outsider ownership: $p_{T}<p_{\alpha S}<p_{S}$.

So with insider ownership and equal shares across firms, the carbon price is between $p_{T}$ and $p_{S}$, as illustrated in Figure 6 .

The line $\alpha \Pi^{\prime}(p)-(1-\alpha) p \Pi^{\prime \prime}(p)$ shows the marginal campaign contributions as a function of the carbon price. For a small $\alpha$ the equilibrium carbon price is close to the carbon securities equilibrium carbon price, for an $\alpha$ close to one the carbon price is close to the price under a carbon tax.

A system based on carbon securities performs better with respect to equilibrium carbon price and the variance of the carbon price than a system based on a carbon tax if at least one of the carbon-using firms does not purchases a share of carbon securities that is equal to its share of carbon emission. This superperfect distribution in which all securities are bought by

\footnotetext{
${ }^{13}$ Carbon-using firms that do not purchase carbon securities always prefer a carbon price equal to zero.
} 


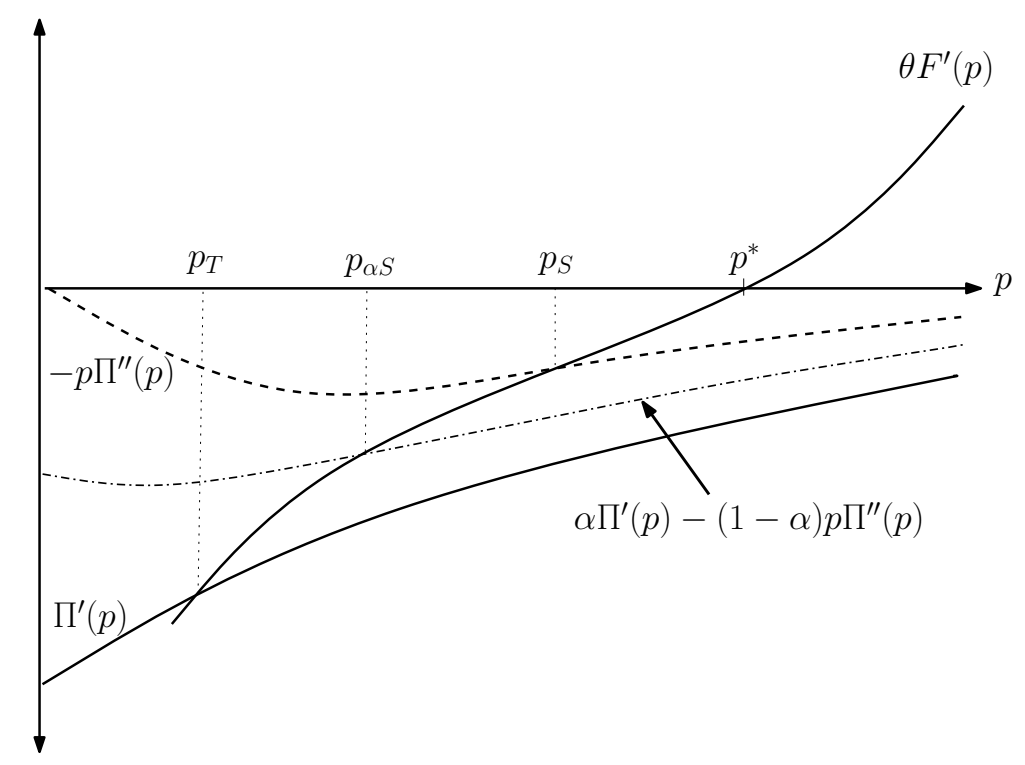

Figure 6: The carbon price if some carbon-using firms purchase securities.

carbon-using firms and each firm purchases a fraction of carbon securities that exactly equals its share of future total emissions is not just highly unlikely to occur in practice but is also undesirable from the perspective of a politician. The reason is that campaign contributions are lower for security distributions close to this superperfect distribution.

A scenario in which some securities are held by carbon using firms and some securities are held by outsiders to the carbon-using industry is not explicitly considered here. This case is analytically equivalent to the scenario discussed above. It makes no difference if a carbon using firm purchases a security for investment purposes or if an outside investor purchases the carbon security for investment purposes. All that matters is what fraction of securities is held for investment purposes or in other words held with the intent to sell allowances. In the case of the $\mathrm{SO}_{2}$ allowances traded under the EPA's Acid Rain Program, non- $\mathrm{SO}_{2}$ emitting entities purchased about 35\% of the allowances auctioned between 2001 and 2011. The vast 
majority of allowances purchased by non- $\mathrm{SO}_{2}$ emitting entities is purchased for investment (resale) purposes.

Apart from a firm's inability to perfectly predict its share of carbon emission relative to everybody else's emissions, the large total value of carbon securities also makes it unlikely that a superperfect distribution of allowances would occur. For example, to purchase the necessary quantity of 15 year maturity securities to cover its emissions, a typically electric utility company may have to spend an amount comparable to its current total assets. ${ }^{14} 15$

Just like a permit system, a carbon securities system can be designed so that there is government revenue from selling or auctioning securities. If securities are auctioned off, theory suggests that the revenue is equal in size to that of a tax that would generate the same amount of emissions. If demand for carbon is inelastic, as we assumed throughout, Proposition 3 implies that government revenue is at least as large and likely larger under the here proposed policy instrument than under alternative policy tools since the carbon price would be higher. The monitoring burden of a system based on carbon securities is likely to be similar to a carbon permit system.

As discussed in Nordhaus (2010a) raising government revenue by setting a price for carbon has many advantages over standard sources of government revenue such as income, consumption and company taxes. A sale of carbon securities would raise a larger amount of money upfront than introducing a carbon tax would. If the revenues from the securities sale were

\footnotetext{
${ }^{14}$ Consider the following example. In 2010, Southern Co emitted 145 million tons of $\mathrm{CO}_{2}$ and had capital expenditures of $\$ 4$ billion, operating revenues of $\$ 17.5$ billion and assets of $\$ 55$ billion (Source: www.southerncompany.com). Assuming securities have a maturity of 15 years and the expected carbon price is constant at $\$ 30$ per ton of carbon over this period, with a discount rate of $5 \%$ the value of the securities Southern Co would have to purchase to cover their emissions is around $\$ 45$ billion. Buying one year's carbon coupons would cost around $\$ 4$ billion.

${ }^{15}$ In addition, carbon securities are financial assets with an uncertain future value. The future value of carbon securities is affected by climate uncertainty, political uncertainty and uncertainty about the demand for fossil fuels. It seems therefore plausible to anticipate that a significant share of securities would be bought by investment banks and other entities specialized on investment in assets with uncertain returns.
} 
used to reduce government debt, this could be a very helpful first step back towards fiscal sustainability.

A question left for future research is what the optimal maturity of carbon securities is. Having carbon securities just pay one carbon allowance is probably not good for lobby formation, but having carbon securities pay carbon allowances for forever may also have some disadvantages.

\section{Concluding Comments}

A carbon policy instrument which allows a group of stakeholders to be developed whose interests are in reducing the carbon emissions will bring the equilibrium emissions closer to the level preferred by voters. From a political economy perspective, a carbon security instrument can incentivize these stakeholders to lobby the government because it will increase the value of their assets. These securities provide the owner with a fraction of the yet to be decided carbon emissions quota. This paper shows that carbon securities have a number

of desirable properties. Importantly, if political uncertainty and climate uncertainty are important concerns, carbon securities can make carbon abatement policy more predictable. A key advantage of carbon securities in this respect may be that they are a very attractive policy instrument from a politician's point of view.

\section{References}

Aidt, Toke S. (1998) "Political internalization of economic externalities and environmental policy," Journal of Public Economics, Vol. 69, No. 1, pp. 1-16.

Allen, Myles R., David J. Frame, Chris Huntingford, Chris D. Jones, Jason A. Lowe, Malte 
Meinshausen, and Nicolai Meinshausen (2009) "Warming caused by cumulative carbon emissions towards the trillionth tonne," Nature, Vol. 458, No. 2, pp. 1163-1166.

Bernheim, B. Douglas and Michael D. Whinston (1986) "Menu Auctions, Resource Allocation, and Economic Influence," The Quarterly Journal of Economics, Vol. 101, No. 1, pp. $1-31$.

Bombardini, Matilde (2008) "Firm heterogeneity and lobby participation," Journal of International Economics, Vol. 75, No. 2, pp. 329 - 348.

Bovenberg, A. Lans, Lawrence H. Goulder, and Mark R. Jacobsen (2008) "Costs of alternative environmental policy instruments in the presence of industry compensation requirements," Journal of Public Economics, Vol. 92, No. 56, pp. 1236 - 1253.

Cooper, John C.B. (2003) "Price elasticity of demand for crude oil: estimates for 23 countries," OPEC Review, Vol. 27, pp. 1-8.

Crocker, Thomas D. (1966) "The Structuring of Atmospheric Pollution Control Systems," in Harold Wolozin ed. The Economics of Air Pollution: W.W. Norton.

Dales, John H. (1968) Pollution, Property and Prices: University of Toronto Press.

Davis, Lucas W. and Erich Muehlegger (2010) "Do Americans Consume Too Little Natural Gas: An Empirical Test of Marginal Cost Pricing," RAND Journal of Economics, Vol. 41, No. 4.

Downs, Anthony (1957) "An Economic Theory of Political Action in a Democracy," Journal of Political Economy, Vol. 65, No. 2, pp. pp. 135-150.

Ekins, Paul and Stefan Speck (1999) "Competitiveness and Exemptions From Environmental Taxes in Europe," Environmental and Resource Economics, Vol. 13, pp. 369-396. 
Goulder, Lawrence H., Ian W.H. Parry, Roberton C. Williams III, and Dallas Burtraw (1999)

"The cost-effectiveness of alternative instruments for environmental protection in a secondbest setting," Journal of Public Economics, Vol. 72, No. 3, pp. 329 - 360.

Grossman, Gene M. and Elhanan Helpman (1994) "Protection for Sale," The American Economic Review, Vol. 84, No. 4, pp. 833-850.

Hahn, Robert W. (2009) "Greenhouse Gas Auctions and Taxes: Some Political Economy Considerations," Review of Environmental Economics and Policy, Vol. 3, No. 2, pp. 167188.

Hanley, Nick and Ian A. MacKenzie (2010) "The Effects of Rent Seeking over Tradable Pollution Permits," The B.E. Journal of Economic Analysis \&\& Policy, Vol. 10, No. 1 (Topics), Article 56 .

Hotelling, Harold (1929) "Stability in Competition," The Economic Journal, Vol. 39, No. 153, pp. pp. 41-57.

Keller, Klaus, Alexander Robinson, David F. Bradford, and Michael Oppenheimer (2007) "The regrets of procrastination in climate policy," Environmental Research Letters, Vol. 2, pp. 1-4.

Keohane, Nathaniel O. (2009) "Cap and Trade, Rehabilitated: Using Tradable Permits to Control U.S. Greenhouse Gases," Review of Environmental Economics and Policy, Vol. 3, No. 1, pp. 42-62.

Keohane, Nathaniel O., Richard L. Revesz, and Robert N. Stavins (2002) "The Choice of Regulatory Instruments in Environmental Policy," Harvard Environmental Law Review, Vol. 22, pp. 313-367. 
Kerr, William R., William F. Lincoln, and Prachi Mishra (2011) "The Dynamics of Firm Lobbying," Working Paper 17577, National Bureau of Economic Research.

Knittel, Christopher R. (2012) "Reducing Petroleum Consumption from Transportation," Journal of Economic Perspecitives, Vol. 26, No. 1, pp. pp. 93-118.

Lai, Yu-Bong (2008) "Auctions or grandfathering: the political economy of tradable emission permits," Public Choice, Vol. 136, No. 1-2, pp. 182-200.

Marceau, Nicolas and Michael Smart (2003) "Corporate Lobbying and Commitment Failure in Capital Taxation," The American Economic Review, Vol. 93, No. 1, pp. pp. 241-251.

Markussen, Peter and Gert Tinggaard Svendsen (2005) "Industry lobbying and the political economy of GHG trade in the European Union," Energy Policy, Vol. 33, No. 2, pp. 245 255.

Marsiliani, Laura and Thomas I. Renström (2000) "Time Inconsistency in Environmental Policy: Tax Earmarking as a Commitment Solution," The Economic Journal, Vol. 110, No. 462, pp. pp. C123-C138.

Metcalf, Gilbert E. (2009) "Designing a Carbon Tax to Reduce U.S. Greenhouse Gas Emissions," Rev Environ Econ Policy, Vol. 3, No. 1, pp. 63-83.

Nordhaus, William D. (2010a) "Carbon Taxes to Move Toward Fiscal Sustainability," The Economists' Voice, Vol. 7, No. 3.

— (2010b) "Economic aspects of global warming in a post-Copenhagen environment," Proceedings of the National Academy of Sciences, Vol. 107, No. 26, pp. 11721-11726.

Oates, Wallace E. and Paul R. Portney (2003) "The political economy of environmental policy," in K. G. Mler and J. R. Vincent eds. Handbook of Environmental Economics, Vol. 1 of Handbook of Environmental Economics: Elsevier, Chap. 8, pp. 325-354. 
Pigou, Arthur Celil (1920) The Economics of Welfare: Macmillian.

Stavins, Robert N. (2004) The Political Economy of Environmental Regulation: Elgar, Edward Publishing.

Stern, Nicholas (2007) The Economics of Climate Change: The Stern Review: Cambridge University Press.

\section{A Mathematical Appendix}

\section{A.1 Equilibrium Carbon Price with a Carbon Tax}

Definition 2 (Equilibrium with a Carbon Tax). An equilibrium of the tax game is a contribution function $C_{E}(p)$ and a carbon price $p$ such that $C_{E}(p)$ and $p$ are an equilibrium of the lobbying stage of the carbon securities game; that is

(i) the contribution function maximizes the joint welfare of the lobby's members given the carbon price $p$

(ii) carbon price p maximizes the government's objective taking the contribution function as given

The following proposition states the necessary and sufficient conditions for an equilibrium of the lobbying stage of the tax game.

Proposition 4. $\left(C_{E}^{0}, p_{T}\right)$ is an equilibrium of the lobbying stage if and only if

a) $C_{E}^{0}$ is feasible

b) $p_{T}$ maximizes $C_{E}(p)-\theta F(p)$

c) $p_{T}$ maximizes $W_{E}(p)-\theta F(p)$ 
d) there exists a $p^{E}$ that maximizes $W_{G}(p)$ such that $C_{E}^{0}\left(p^{E}\right)=0$

Proof. The proposition follows immediately from Lemma 2 of Bernheim and Whinston (1986). The first condition of the proposition is a standard feasibility condition. The second condition requires that the carbon price is optimal for the government since $C_{E}(p)-\theta F(p)$ is the government revenue. The third and fourth conditions together state that the lobby's contribution schedule has to be optimal.

Proof of Equation (7). Equation (7) is derived from Proposition 4. The first order condition is unique if the contribution schedule is truthful. Note that condition (b) of Proposition 4 simplifies to

$$
W_{E}(p)-B_{E}-\theta F(p)
$$

where $B_{E}$ is a constant. Therefore, conditions (b) and (c) of Proposition 4 lead to the same first order condition. Second, to see that the equilibrium carbon price $p_{T}$ satisfies $\theta F^{\prime}(p)=\Pi^{\prime}(p)$ start with either condition (b) and (c) of Proposition 4 and replace $W_{E}$ with the expression in (4). This yields

$$
\Pi(p)-B_{E}-\theta F(p)
$$

Therefore, the FOC characterizing the equilibrium of the tax game is $\theta F^{\prime}(p)=\Pi^{\prime}(p)$.

Proof of Proposition 1. Since $p \geq 0$ is an input price $\Pi(p)$ is a decreasing function of $p$ : $\Pi^{\prime}(p)<0$. This implies that $p_{T}$ has to be in the range of $p$ in which it holds that $\theta F^{\prime}(p)<0$. Since $F$ by assumption has a unique minimum, $p^{*}$, it follows that $\theta F^{\prime}(p)<0$ for all $p<p^{*}$. Therefore, $p_{T}<p^{*}$.

\section{A.2 Equilibrium with Carbon Securities}

Definition 3 (Equilibrium with Carbon Securities). An equilibrium of the carbon securities game is a set of contribution functions $\left\{C_{E}(p), C_{B}(p)\right\}$ and a carbon price $p$ such that 
$\left\{C_{E}(p), C_{B}(p)\right\}$ and $p$ are an equilibrium of the lobbying stage of the carbon securities game; that is

(i) each contribution function maximizes the joint welfare of the group's members given the carbon price and the other groups contribution function

(ii) carbon price p maximizes the government's objective taking the contribution function as given

Proposition 5. $\left(C_{B}^{*}, C_{E}^{*}, p_{S}\right)$ is an equilibrium of the lobbying stage if and only if

a) $C_{E}^{*}, C_{B}^{*}$ are feasible

b) $p_{S}$ maximizes $C_{B}(p)+C_{E}(p)-\theta F(p)$

c) $p_{S}$ maximizes $W_{B}(p)-\theta F(p ; I)+C_{E}(p)$

d) there exists a $p^{B}$ that maximizes $W_{G}(p)$ such that $C_{B}^{*}\left(p^{B}\right)=0$

e) $p_{S}$ maximizes $W_{E}(p)-\theta F(p)+C_{B}(p)$

f) there exists a $p^{E}$ that maximizes $W_{G}(p)$ such that $C_{E}^{*}\left(p^{E}\right)=0$

Proof. See Proposition 4.

Proof of Equation (8). Uniqueness under truthful strategies follows directly from Propositions 5 and the definition of truthful strategy. With truthful contributions,

$$
C_{B}(p)=W_{B}(p)-B_{B}
$$

and

$$
C_{E}(p)=W_{E}(p)-B_{E}
$$


so that conditions (b), (c) and (e) lead to the same first order condition. Next, substitute the relevant terms. The government chooses $p_{S}$ to maximize

$$
-p \Pi^{\prime}(p)-\xi n-\theta F(p)+\Pi(p)
$$

Therefore, the first order condition that characterizes the equilibrium of the carbon securities is $\theta F^{\prime}(p)=-p \Pi^{\prime \prime}(p)$.

Proof of Proposition 2. Similar to the proof of Proposition 1. For all $p \geq 0$, marginal campaign contributions $-p \Pi^{\prime \prime}(p) \leq 0$. It follows from the properties of the $F$ that $p_{T}<p_{S}$.

\section{A.3 Equilibrium Carbon Price if some Carbon-Using Firm Hold Securities}

Suppose that $\alpha m$ firms each purchase $\frac{1}{\alpha m} n$ securities and the remaining $(1-\alpha) m$ firms do not purchase any securities. The two groups of firms have different preferences, therefore it makes sense for them to form separate lobbies. Each lobby attempts to affect the carbon price in their favor. Their gross of contributions payoff of the $(1-\alpha) m$ firms that did not purchase any carbon securities is

$$
W_{E(1-\alpha)}(p)=(1-\alpha) \Pi(p)
$$

and the gross of contributions payoff of the $\alpha m$ firms that purchased carbon securities is

$$
W_{E \alpha}(p)=\alpha \Pi(p)-(1-\alpha) p \Pi^{\prime}(p)-\xi n \text {. }
$$

The government maximizes the weighted difference of campaign contributions and cost of deviating from voters' opinion. $W_{G}$ denotes the welfare of the government:

$$
W_{G}(p)=C_{E(1-\alpha)}(p)+C_{E \alpha}(p)-\theta F(p)
$$

The first order condition describing the equilibrium is

$$
\alpha \Pi^{\prime}(p)-(1-\alpha) p \Pi^{\prime \prime}(p)-\theta F^{\prime}(p)=0 .
$$


Recall from Equations (7) and (8) that the equilibrium condition characterizing the first order condition of the tax game (equivalent to $\alpha=1$ ) is

$$
\Pi^{\prime}(p)-\theta F^{\prime}(p)=0
$$

and the first order condition of the carbon securities game $(\alpha=0)$ is

$$
-p \Pi^{\prime \prime}(p)-\theta F^{\prime}(p)=0 .
$$

Therefore the equilibrium price in the case considered here, $p_{\alpha S}$, satisfies $p_{T} \leq p_{\alpha S} \leq p_{S}$. 